\title{
Efficacy and safety of nasal high-flow oxygen in COPD patients
}

Helene Vogelsinger ${ }^{1}\left(\mathbb{D}\right.$, Michael Halank ${ }^{2}$, Silke Braun², Heinrike Wilkens ${ }^{3}$, Thomas Geiser ${ }^{4}$, Sebastian Ott ${ }^{4}$, Armin Stucki ${ }^{5}$ and Christian M. Kaehler ${ }^{1,6^{*}}$

\begin{abstract}
Background: Nasal high-flow oxygen therapy (HFOT) is a novel treatment option for patients suffering from acute or chronic respiratory failure. Aim of our study was to compare safety and efficacy of HFOT with those of conventional oxygen treatment (COT) in normo- and hypercapnic COPD patients.

Methods: A single cohort of 77 clinically stable hypoxemic patients with an indication for long-term oxygen treatment (LTOT) with or without hypercapnia successively received COT and HFOT for 60 min each, including oxygen adaption and separated by a 30 min washout phase.

Results: HFOT was well-tolerated in all patients. A significant decrease in $\mathrm{PaCO}_{2}$ was observed during oxygen adaption of HFOT, and increased $\mathrm{PaO}_{2}$ coincided with significantly increased $\mathrm{SpO}_{2}$ and decreased $\mathrm{AaDO}_{2}$ during both treatment phases. Even at a flow rate of $15 \mathrm{~L} / \mathrm{min}$, oxygen requirement delivered as air mixture by HFOT tended to be lower than that of COT (2.2 L/min). Not only was no increase in static or dynamic lung volumes observed during HFOT, but even was a significant reduction of residual lung volume measured in 36 patients (28\%).

Conclusions: Thus, short-term use of HFOT is safe in both normocapnic and hypercapnic COPD patients. Lower oxygen levels were effective in correcting hypoxemic respiratory failure and reducing hypercapnia, leading to a reduced amount of oxygen consumption. Long-term studies are needed to assess safety, tolerability, and clinical efficacy of HFOT.

Trial registration: ClinicalTrials.gov NCT01686893 13.09.2012 retrospectively registered (STIT-1) and NCT01693146 14.09. 2012 retrospectively registered (STIT-2). Studies were approved by the local ethics committee (Ethikkommission der Medizinischen Universität Innsbruck, Studienkennzahl UN3547, Sitzungsnummer 274/4.19).
\end{abstract}

Keywords: High-flow oxygen, short-term nasal highflow., COPD., normocapnic., hypercapnic.

\section{Summary}

Short-term nasal highflow oxygen therapy (HFOT) is safe and efficacious in normocapnic and hypercapnic COPD patients.

\section{Background}

Nasal high-flow oxygen therapy (HFOT) is a novel noninvasive alternative to conventional oxygen treatment $(\mathrm{COT})$ and an alternative to non-invasive ventilation in selected patients. It is based on the transnasal application of a preheated and moistened air-oxygen

\footnotetext{
* Correspondence: c.m.kaehler@i-med.ac.at

${ }^{1}$ Pneumology, Internal Medicine II, Department of Internal Medicine, Medical University of Innsbruck, Innsbruck, Austria

${ }^{6}$ Pneumology, Lung Centre Southwest, Wangen im Allgäu, Germany

Full list of author information is available at the end of the article
}

composition at high flow rates $[1,2]$. Besides pharmaceutical treatment options, long-term oxygen treatment (LTOT) and non-invasive ventilation have become a main emphasis in the therapy of respiratory insufficiency including chronic obstructive pulmonary disease (COPD), sleep apnoea, pulmonary oedema, and other conditions [3]. The prevalence of COPD worldwide is between 9 and $10 \%$ in people over the age of 40 , with the incidence significantly varying between countries, i.e. ranging from $0.2 \%$ in Japan to $37 \%$ in the USA. Men are more often affected than women $[4,5]$. According to the WHO, COPD is the fourth leading cause of death and is supposed to become the third leading cause by 2020 [6]. COPD is marked by an airflow limitation with persistent and progressive courses of breathlessness, frequently associated with chronic productive cough and chest tightness [7]. 
As a conventional treatment option, typically applied in case of persistent hypoxaemia $\left(\mathrm{PaO}_{2}<55 \mathrm{mmHg}\right.$ or $<60 \mathrm{mmHg}$ upon signs of right heart failure or polycythaemia), LTOT via a nasal cannula or oxygen mask has been successfully performed for decades. So far, LTOT represents the only life-extending therapy in severe lung disease $[8,9]$. However, long-term modes of treatment remain inapplicable in patients with restricting factors and usually lead to limitations in the patients' mobility and quality of life [10]. Recent studies illustrated further limitations of conventional LTOT, becoming particularly evident in cases of exacerbations or at later stages of the disease [11]. As an optional way of treatment that recently moved into focus, HFOT has been investigated, and specific devices such as $\mathrm{TNI}^{\circ} 20$ oxy (TNI medical AG, Würzburg, Germany) have been developed [12]. For HFOT, humidification and preheating of the applied gas offers a suitable precondition to achieve high flow rates and prevent airway dehydration. An obvious advantage of nasal application over respiratory masks lies in improved ways of daily activity, free ability to communicate, and higher levels of compliance [13].

Successful applications of HFOT in the past included paediatric treatments, in which intubation or continuous positive airway pressure could be prevented, and the treatment of respiratory distress syndrome [14]. Similarly, treatment approaches in premature infants have been shown to exert beneficial effects in cases of apnoea and other indications in children, such as infectious bronchiolitis, pneumonia, and congestive heart failure $[14,15]$. A number of recent clinical investigations provided a strong input to the HFOT strategy and underlined the benefits of various HFOT applications [16-20].

So far, however, clear information is limited on whether HFOT is reliably beneficial for the broader treatment of respiratory insufficiencies and may provide advantages over conventional forms of therapy. In this study, the question was addressed whether HFOT provides the same safety and efficacy as COT in the treatment of hypoxaemic COPD patients with both normoor hypercapnia. Primary and secondary endpoints of the study were set as changes in the partial oxygen and carbon dioxide pressure $\left(\mathrm{PaO}_{2}, \mathrm{PaCO}_{2}\right)$, the alveolar to arterial oxygen pressure difference $\left(\mathrm{AaDO}_{2}\right)$, and peripheral oxygen saturation $\left(\mathrm{SpO}_{2}\right)$ at a defined oxygen flow rate, as well as safety of HFOT as assessed by lung volume changes. Thus, our study verifies for the first time that HFOT is safe and efficacious in COPD patients with or without hypercapnia.

\section{Methods}

\section{Study population}

The study population comprised a single cohort of 77 COPD patients, who were already treated by conventional LTOT and stabilized, then awaiting a potential inclusion into the subsequent HFOT studies STIT-1 and -2 (Short Time TNI Treatment). Inclusion criteria of the STIT-1 study on normocapnic COPD patients were defined by the indication for LTOT $\left(\mathrm{PaO}_{2}<\right.$ $55 \mathrm{mmHg}$ or $<60 \mathrm{mmHg}$ upon signs of right heart failure or polycythaemia), age 30-80 years, and functional class COPD GOLD IV (as defined by $\mathrm{FEV}_{1} / \mathrm{FVC}<70 \%$, post-bronchodilator forced expiratory volume in $1 \mathrm{~s}$ $\left[\mathrm{FEV}_{1}\right]<30 \%$ pred., or $<50 \%$ pred. With LTOT indication). Two groups were defined by the postbronchodilator $\mathrm{FEV}_{1}$, with group 1 corresponding to $30 \%$ pred. $\leq \mathrm{FEV}_{1}<50 \%$ pred. And group 2 corresponding to $\mathrm{FEV}_{1}<30 \%$ pred. [21]. The number of patients announced/analysed was 50/50 in STIT-1. Inclusion criteria of the STIT-2 study on hypercapnic COPD patients were an indication for LTOT (see above), $\mathrm{PaCO}_{2}>$ $45 \mathrm{mmHg}$ at rest without oxygen supplementation, age 30-85 years, and functional class COPD GOLD IV (see above). The number of patients announced/analysed was 20/27. Exclusion criteria in both studies were clinical instability, lack of option for testing lung function, exacerbation within the last 14 days, serious concomitant diseases, severe anaemia (haemoglobin $<8.5 \mathrm{~g} / \mathrm{L}$ ), missing consent or participation in any other ongoing study. Any oral or inhaled medication approved for COPD therapy was allowed. Studies STIT-1 and STIT-2 lasted from $02 / 08$ and $11 / 11$ (first patient first visit) to $12 / 11$ and $06 / 12$, respectively. Both studies were extended to 06/14. Studies were registered at ClinicalTrials.gov NCT01686893 (STIT-1 [22]) and NCT01693146 (STIT2 [23]) and approved by the local ethics committee.

\section{Study design}

This prospective study was directed to a single cohort of patients participating in sub study STIT-1 or STIT-2. During the screening visit, arranged 2 weeks prior to start of each sub study, informed consent was obtained. Every patient was informed about the new method of HFOT and its possible effects for COPD patients, furthermore about the course of the study and the extra investigations during the study. The patient's history as well as demographic and clinical parameters were assessed. Patients $(n=77)$ received first COT, which was followed by HFOT, each for 60 min including initial oxygen adaption (see below). For COT, oxygen was applied using the hospital's standard oxygen system and standard nasal prongs, and $\mathrm{TNI}^{\circ} 20$ oxy (TNI medical AG, Würzburg, Germany) was employed as HFOT device. Both treatment phases were separated by a $30 \mathrm{~min}$ washout phase in a sitting position, without oxygen (see below). Physical examinations, analysis of vital signs, and blood gas analysis were performed repeatedly as follows: at the screening visit, at baseline, during both oxygen 
adaption phases, after the $30 \mathrm{~min}$ washout phase, and after COT and HFOT treatment. Bodyplethysmography, spirometry and DLCO (diffusing capacity of lung carbon monoxide) measurement were performed at the screening visit, at baseline and after COT and HFOT. Primary endpoint was the change in $\mathrm{PaO}_{2}$ in the arterialised capillary blood (blood gas analysis) at a defined oxygen flow rate $(\mathrm{L} / \mathrm{min})$. Secondary endpoints were changes in $\mathrm{SpO}_{2}, \mathrm{PaCO}_{2}$ and $\mathrm{AaDO}_{2}$ in the arterialised capillary blood (blood gas analysis) at a defined oxygen flow rate (L/min), and safety of the device in normocapnic (STIT1) and hypercapnic COPD patients (STIT-2), as defined as no increase in the residual volume (RV) and the total lung capacity (TLC) $>15 \%$ of the mean actual value. After treatment, patient satisfaction was assessed in non-standardized surveys.

\section{Oxygen adaptation of COT and HFOT}

Oxygen adaption of both COT and HFOT followed the same standard protocol. Nasal oxygen insufflation with conventional oxygen started at $0.5 \mathrm{~L} / \mathrm{min}$ and was increased in steps of 0.5 to $1 \mathrm{~L} / \mathrm{min}$ until $\mathrm{PaO}_{2}$ was $>60 \mathrm{mmHg}$ or $\mathrm{PaO}_{2}$ increased by $\geq 10 \mathrm{mmHg}$ as compared to the initial value. After successful adaptation, patients received nasal oxygen insufflation at the established flow rate for the remaining duration of the hour to be completed. Blood gas analysis, performed after $10 \mathrm{~min}$ at a defined flow rate, was mandatory at the beginning of oxygen adaptation and was completed $1 \mathrm{~h}$ thereafter. Oxygen flow rate could be increased without blood gas analysis if a $\mathrm{SpO}_{2}>90 \%$ was not reached. A 30 min washout phase at rest, in a sitting position, without oxygen then followed COT. During the washout phase, $\mathrm{PaO}_{2}$ should decline to initial levels $( \pm 2 \mathrm{mmHg}$ ). Adaptation to the HFOT phase was achieved by titration starting from room air conditions (oxygen admixture $0 \mathrm{~L} / \mathrm{min}$ ) towards a nasal oxygen insufflation of $15 \mathrm{~L} /$ min, under oxygen admixture steps of $0.5 \mathrm{~L} / \mathrm{min}$ until reaching a value of $\mathrm{PaO}_{2}>60 \mathrm{mmHg}$ or an increase of $\geq 10 \mathrm{mmHg}$ (in contrast, adaptation to COT started at $0.5 \mathrm{~L} / \mathrm{min}$ ). All subsequent steps followed the protocol described above.

\section{Procedures}

For clinical examinations, vital signs (blood pressure and heart rate) were measured at the beginning and at the end of each point of the study. Blood gases were taken from the hyperaemic ear lobe (anointed with Finalgon [Boehringer-Ingelheim] to increase perfusion) with a single-use system. Hyperaemisation leads to arterialisation of capillary blood, thus the arterial values $\left(\mathrm{PaO}_{2}\right.$, $\mathrm{PaCO}_{2}$ ) are reflected adequately. The collected blood samples were analysed with a routinely used and daily calibrated blood gas analysis device within 2 min after puncture. The bodyplethysmography, spirometry and DLCO measurements comprised the assessment of dynamic and static lung parameters as follows: (i) dynamic volumes such as $\mathrm{FEV}_{1} \%$ (forced expiratory volume in 1 s), RAW (airway resistance) and (ii) static volumes such as ERV (expiratory reserve volume), IC (inspiratory capacity), VC (vital capacity, Vcex and Vcin), RV (residual volume), and TLC (total lung capacity). Static and dynamic lung volumes were recorded with the MasterScreen Body® (CareFusion, Hoechberg, Germany) and Pneumotach $\subset$ (Jaeger, Würzburg, Germany) providing flow measurements in a range up to $20 \mathrm{~L} / \mathrm{s}$ and an accuracy of $\pm 2 \%$. Volume determination was performed by digital integration within a range of $\pm 20 \mathrm{~L}$ and an accuracy of $\pm 3 \%$ or $\pm 50 \mathrm{ml}$. Pressure measurements were piezoresistive with an accuracy of $\pm 2 \%$.

\section{Statistic evaluation}

For statistical analyses, continuous data were described in terms of number, minimum, maximum, mean value, median, and standard deviation. Discrete data sets were described in terms of number and percentage. To investigate differences in oxygen quantities, a paired sample test was used. As the central issue of statistical evaluation, the oxygen flow required to achieve a $\mathrm{PaO}_{2}$ of $>60 \mathrm{mmHg}$ or an increase by at least $10 \mathrm{mmHg}$ when using COT were contrasted to HFOT. The software used was SPSS Statistics 15.0. All values are given as mean $\pm \mathrm{SD}$, and data were considered as significant by the Student's t-test when $p<0.001$.

\section{Results}

\section{Patient characteristics}

Characteristics of the study population, based on defined inclusion and exclusion criteria, is depicted in Fig. 1. Patients of both sub studies were, on average, $66.2 \pm$ 8.5 years old (range 47-84 years), and males were predominant (74\%). Their mean $\mathrm{FEV}_{1}$ was $31.0 \pm 11.4 \%$ of the predicted value, and patients were classified into FEV $130-50 \%$ pred. $(n=38)$ and $\mathrm{FEV}_{1}<30 \%$ pred. $(n=$ 39). At screening visit, mean $\left( \pm\right.$ SD) $\mathrm{PaO}_{2}$ and $\mathrm{PaCO}_{2}$ values were $49.6 \pm 6.2 \mathrm{mmHg}$ and $43.2 \pm 6.3 \mathrm{mmHg}$, respectively, with a $\mathrm{SpO}_{2}$ at $91 \pm 2 \%$. Mean LTOT oxygen flow rates $( \pm \mathrm{SD})$ of $2.2 \pm 1.6 \mathrm{~L} / \mathrm{min}$ (anamnestic) indicated that patients were clinically stable (table 1 ).

\section{Blood gas analysis and oxygen requirement}

Patients $(n=77)$ successively received COT and HFOT, each for $60 \mathrm{~min}$ and separated by a $30 \mathrm{~min}$ washout phase (Fig. 2). Blood gas and vital signs were analysed at the screening visit, at baseline, after oxygen adaption $\left(\mathrm{PaO}_{2}>\right.$ $60 \mathrm{mmHg}$ or increased by $\geq 10 \mathrm{mmHg}$ when compared to baseline), and at the end of each treatment. Bodyplethysmography, spirometry and DLCO measurements were 


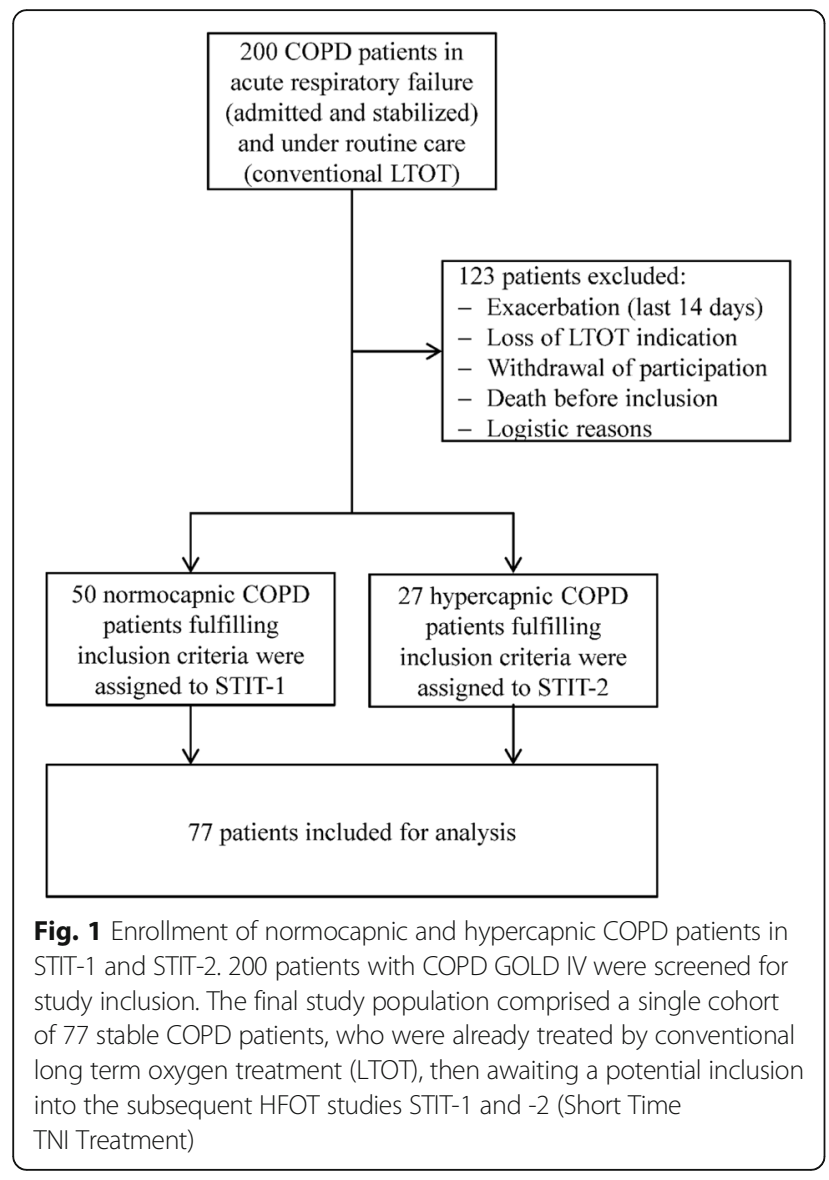

performed at the screening visit, at baseline, and at the end of each 1-h treatment session.

The starting mean baseline $\mathrm{PaO}_{2}$ of $49.6 \pm 6.2 \mathrm{mmHg}$ and $48.7 \pm 5.8 \mathrm{mmHg}$ increased to $63.8 \pm 5.1 \mathrm{mmHg}$ and $61.4 \pm 6.0 \mathrm{mmHg}$ during oxygen adaption of COT and

Table 1 Patient characteristics and lung function at screening visit

\begin{tabular}{|c|c|c|c|}
\hline & STIT-1 & STIT-2 & STIT-1 + 2 \\
\hline \multicolumn{4}{|l|}{ Patient demographics } \\
\hline Sample size (n) & 50 & 27 & 77 \\
\hline Sex (male/female) & $42 / 8$ & $15 / 12$ & $57 / 20$ \\
\hline Age, years (mean $\pm S D$ ) & $67.2 \pm 8.5$ & $64.4 \pm 8.2$ & $66.2 \pm 8.5$ \\
\hline FEV 1 group: $30-50 \%(n)$ & 31 & 7 & 38 \\
\hline FEV 1 group: $<30 \%(n)$ & 19 & 20 & 39 \\
\hline \multicolumn{4}{|l|}{ Lung function } \\
\hline pred. FEV $1, \%($ mean \pm SD) & $34.5 \pm 11.2$ & $24.9 \pm 9.2$ & $31.0 \pm 11.4$ \\
\hline $\mathrm{LTOT}, \mathrm{O}_{2} \mathrm{~L} / \mathrm{min}$ (mean $\pm \mathrm{SD}$ ) & $2.2 \pm 1.7$ & $2.4 \pm 1.4$ & $2.2 \pm 1.6$ \\
\hline $\mathrm{PaO}_{2}, \mathrm{mmHg}($ mean $\pm \mathrm{SD})$ & $51.0 \pm 6.1$ & $47.0 \pm 5.6$ & $49.6 \pm 6.2$ \\
\hline $\mathrm{PaCO}_{2}, \mathrm{mmHg}($ mean $\pm \mathrm{SD})$ & $40.0 \pm 4.1$ & $49.1 \pm 5.4$ & $43.2 \pm 6.3$ \\
\hline $\mathrm{SpO}_{2}(\%)$ & $91 \pm 2$ & $89 \pm 3$ & $91 \pm 2$ \\
\hline
\end{tabular}

$\mathrm{FEV}_{1}$ : forced expiratory volume in $1 \mathrm{~s}$; LTOT: long term oxygen therapy
HFOT, respectively, and remained constant during the remaining hour of treatment (Fig. 3).

After both treatments, $\mathrm{SpO}_{2}$ baseline levels were significantly increased $(p<0.0001$; data not shown). HFOT reduced $\mathrm{PaCO}_{2}$ levels already during oxygen adaptation $(-2.36 \mathrm{mmHg}, p<0.038)$ which remained on a lower level until the end of treatment $(-2.11 \mathrm{mmHg}, p<$ 0.077). In contrast, $\mathrm{PaCO}_{2}$ slightly increased during COT (Fig. 3), and $\mathrm{PaCO}_{2}$ differences between COT and HFOT were significant after both oxygen adaptation and 1 -h treatment session $(p<0.0001)$. Under these HFOT conditions (constant flow rate of $15 \mathrm{~L} / \mathrm{min}$ ), overall oxygen requirement of HFOT was lower than that of COT in normocapnic $(1.87 \pm 1.57 \mathrm{~L} / \mathrm{min}$ vs. $2.07 \pm 1.65 \mathrm{~L} / \mathrm{min})$ and hypercapnic $(2.09 \pm 1.14 \mathrm{~L} / \mathrm{min}$ vs. $2.15 \pm 1.37 \mathrm{~L} /$ min,) COPD patients.

Figure 4 shows the combined data for both normocapnic and hypercapnic patients, demonstrating the reduced amount of oxygen required to achieve comparable oxygenation during HFOT $(1.95 \pm 1.45 \mathrm{~L} / \mathrm{min}$ vs. $2.1 \pm$

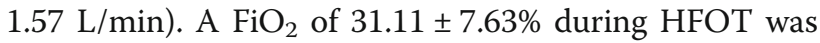
documented to achieve required patients' oxygenation. Of note, in some cases $(n=6)$, in which the patient's need of oxygen remained moderately low, room air concentrations were sufficient for HFOT without any oxygen admixture. In addition, $\mathrm{AaDO}_{2}$ declined from 50.33 to $35.87 \mathrm{mmHg}$ under COT and from 51.91 to $39.49 \mathrm{mmHg}$ under HFOT, respectively, with each decrease being significant $(p<0.0001)$.

\section{Safety}

No alterations of lung function parameters were detected during the study period (Fig. 5). Interestingly, in $28 \%$ of patients (36/77), the RV was significantly lower after HFOT than that after COT $(4.17 \pm 1.03 \mathrm{~L}$ vs. 4.68 $\pm 1.53 \mathrm{~L} ; p<0.0001)$. In addition, there were no significant differences in DLCO $(3.96 \pm 1.59 \mathrm{mmol} / \mathrm{min} / \mathrm{kPa}$ vs. $3.89 \pm 1.51 \mathrm{mmol} / \mathrm{min} / \mathrm{kPa}$ ) and RAW after both treatment regimens $(0.83 \pm 0.84 \mathrm{kPa} / \mathrm{L} / \mathrm{s}$ vs. $0.87 \pm 0.57 \mathrm{kPa} /$ $\mathrm{L} / \mathrm{s})$. No adverse events and no significant alterations in blood pressure or cardiac frequency were noted. HFOT was well tolerated by all 77 patients.

\section{Discussion}

In this study, we analysed HFOT as a novel treatment option for chronic hypoxaemic respiratory failure in both normocapnic and hypercapnic COPD patients, and compared it to the classical mode of COT concerning efficacy of oxygenation and safety. The main results of the study were that (i) HFOT was well-tolerated by all 77 patients, (ii) the level of oxygen requirement (FiO2) was generally lower under HFOT, (iii) hypercapnia was significantly reduced under HFOT, and (iv) HFOT was safe as no increase in residual volumes or any alteration of 


Fig. 2 Study procedures and measurements. Stable patients with COPD GOLD IV ( $n=77)$ successively received conventional oxygen therapy
(COT) and nasal high-flow oxygen therapy (HFOT), each for 60 min and separated by a 30 min washout phase. Blood gas and vital signs were
analysed at the screening visit, at baseline, after oxygen adaption (PaO ${ }_{2}>60 \mathrm{mmHg}$ or increased by $\geq 10$ mmHg when compared to baseline),
and at the end of each treatment. Bodyplethysmography, spirometry and $\mathrm{DLCO}$ measurements were performed at the screening visit, at baseline,
and at the end of each 1-h treatment session

total lung volumes occurred. We therefore conclude that HFOT offers therapeutic benefits for both normocapnic and hypercapnic COPD patients as a new procedure for the future. As compared to standard therapy (COT), lower levels of oxygen were effective in correcting hypoxaemic respiratory failure and reducing hypercapnia, ultimately leading to an economization of oxygen consumption.

To date, COT has been the most frequently used oxygenation assistance (LTOT) in the therapy of severe COPD that was shown to improve survival. With HFOT, a completely new method has recently been introduced. However, data on safety in severely ill COPD patients with hypoxaemia, hyperinflation and consequently hypercapnia are still missing. Therefore, the aim of our study was to examine general parameters of reliability and usefulness in the treatment of severe COPD. Under HFOT, $\mathrm{PaO}_{2}$ substantially increased and remained constant throughout the period of treatment. Likewise, $\mathrm{SpO}_{2}$ was significantly increased, while $\mathrm{PaCO}_{2}$ levels already declined during oxygen adaptation of HFOT. Furthermore, also
$\mathrm{AaDO}_{2}$ was significantly reduced by both COT and HFOT.

Regarding oxygenation, HFOT seems to be superior to COT. In our experiments lower $\mathrm{FiO} 2$ rates were necessary to achieve the predefined $\mathrm{PaO}_{2}$ in our patients. Utilizing COT $100 \%$ of oxygen is inspired. Wettstein et al. reported that using $\mathrm{COT} \mathrm{FiO} 2$ increases with increasing flow rates. COT was delivered at a mean flow rate of 2.2 $\pm 1.6 \mathrm{~L} / \mathrm{min}$. In the data published by Wettstein and colleagues a pharyngeal $\mathrm{FiO} 2$ of 0.30 to 0.38 can be measured at a COT flow rate of $2 \mathrm{~L} / \mathrm{min}$. However, also $\mathrm{FiO}_{2}$ of $31.11 \pm 7.63 \%$ during HFOT was measured with higher flow rates and applying an air/oxygen mixture. Higher flow rates might even further reduce oxygen demand in these patients, which might be of socioeconomical relevance.

Thus, one of the essential findings was the clear reduction of $\mathrm{PaCO}_{2}$ during HFOT compared to COT as verified in both subgroups of the patient collective. As a potential reason, an improved washout effect of the nasopharyngeal dead space or, alternatively, an increase

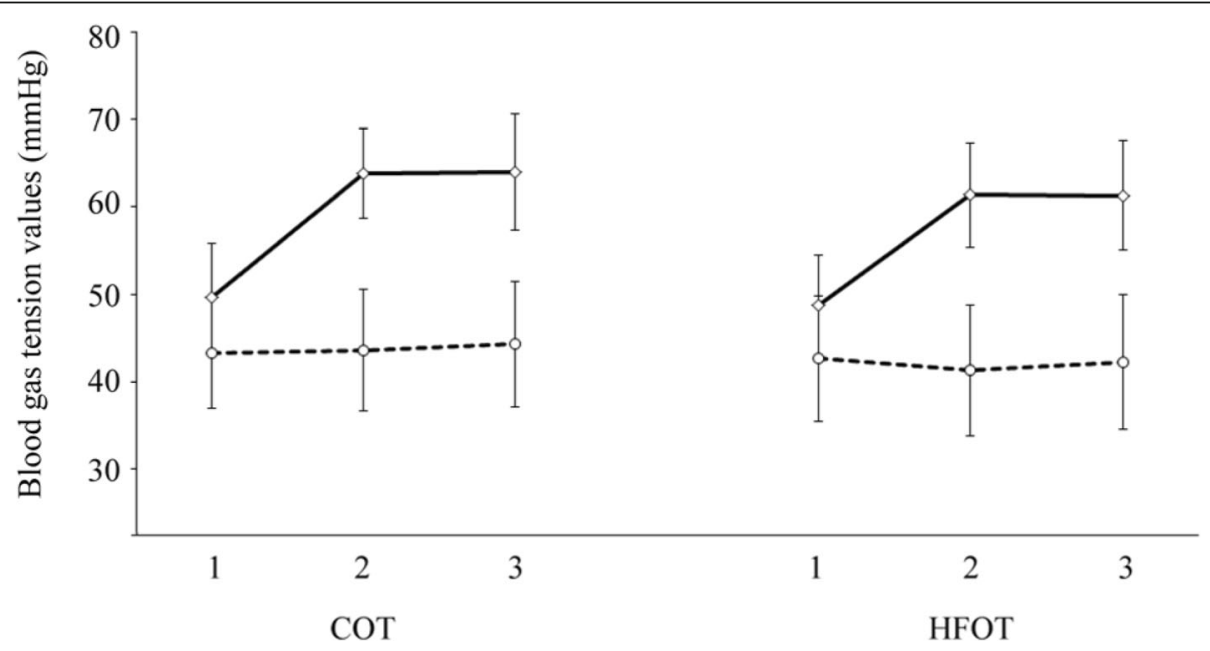

Fig. 3 Mean blood gas values during conventional oxygen therapy (COT) and nasal high-flow oxygen therapy (HFOT). Blood samples ( $\mathrm{n}=77)$ were subjected to measurements of $\mathrm{PaCO}_{2}$ (dotted line) and $\mathrm{PaO}_{2}$ (solid line) at baseline (1), after 10-60 min of oxygen adaptation until reaching a value of $\mathrm{PaO}_{2}>60 \mathrm{mmHg}$ or an increase of $\geq 10 \mathrm{mmHg}$ (2), and at the end of the 60-min treatment period [including adaption] (3) 


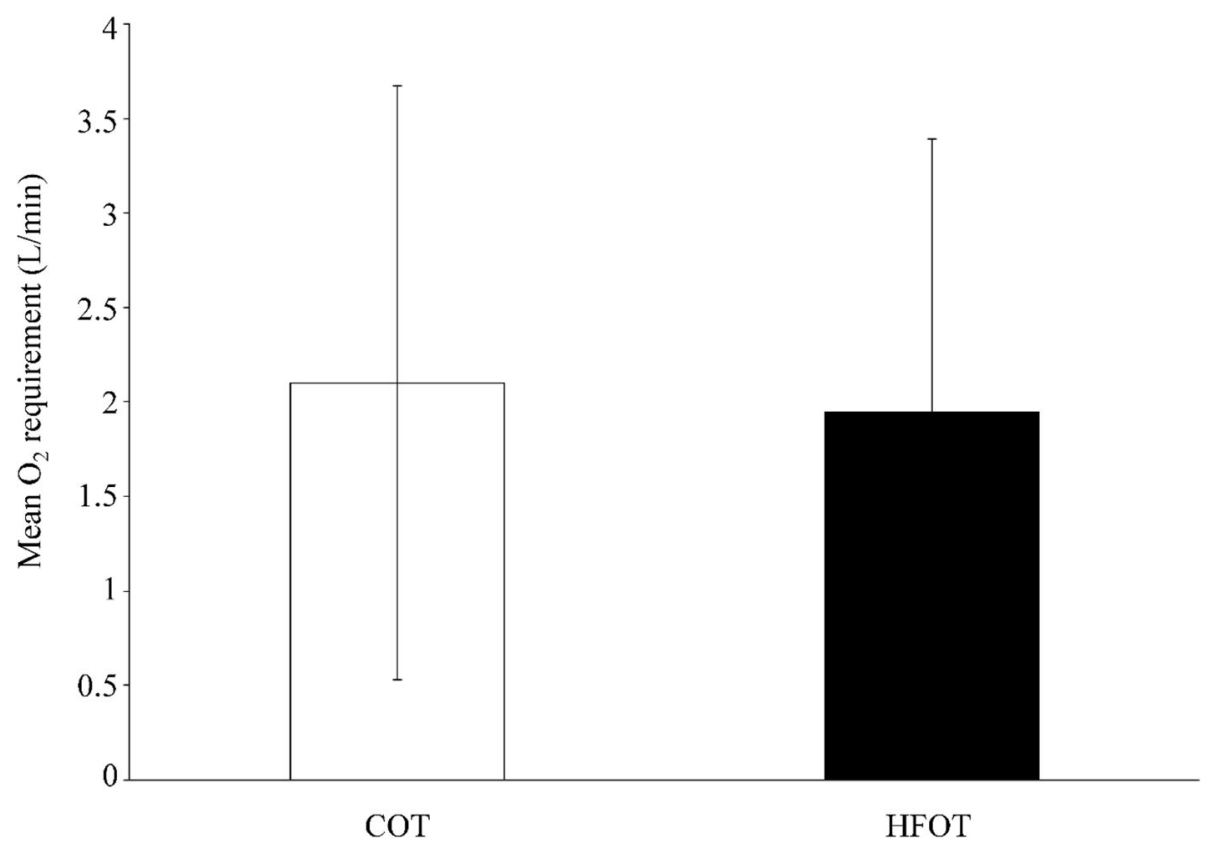

Fig. 4 Oxygen requirement during nasal high-flow oxygen therapy (HFOT). Mean oxygen consumption during conventional oxygen therapy (COT) and HFOT was recorded in 77 patients with stable COPD GOLD IV(combining 50 normocapnic and 27 hypercapnic COPD patients), as assessed by blood gas analysis

in pharyngeal pressure due to the elevated flow rate under HFOT appears plausible [14]. Hereby, the decrease of $\mathrm{PaCO}_{2}$ in hypercapnic patients needs to be stressed as a quality of particular importance since it lowers the risk of respiratory arrest, especially in cases of acute exacerbation. This finding is supported by previous studies showing a significant decline in $\mathrm{PaCO}_{2}$ with HFOT [12, 24]. Frizzoli et al. [24] observed decreasing $\mathrm{PaCO}_{2}$ with rising flow and explained the effect with improved wash out efficiency of the nasopharyngeal dead

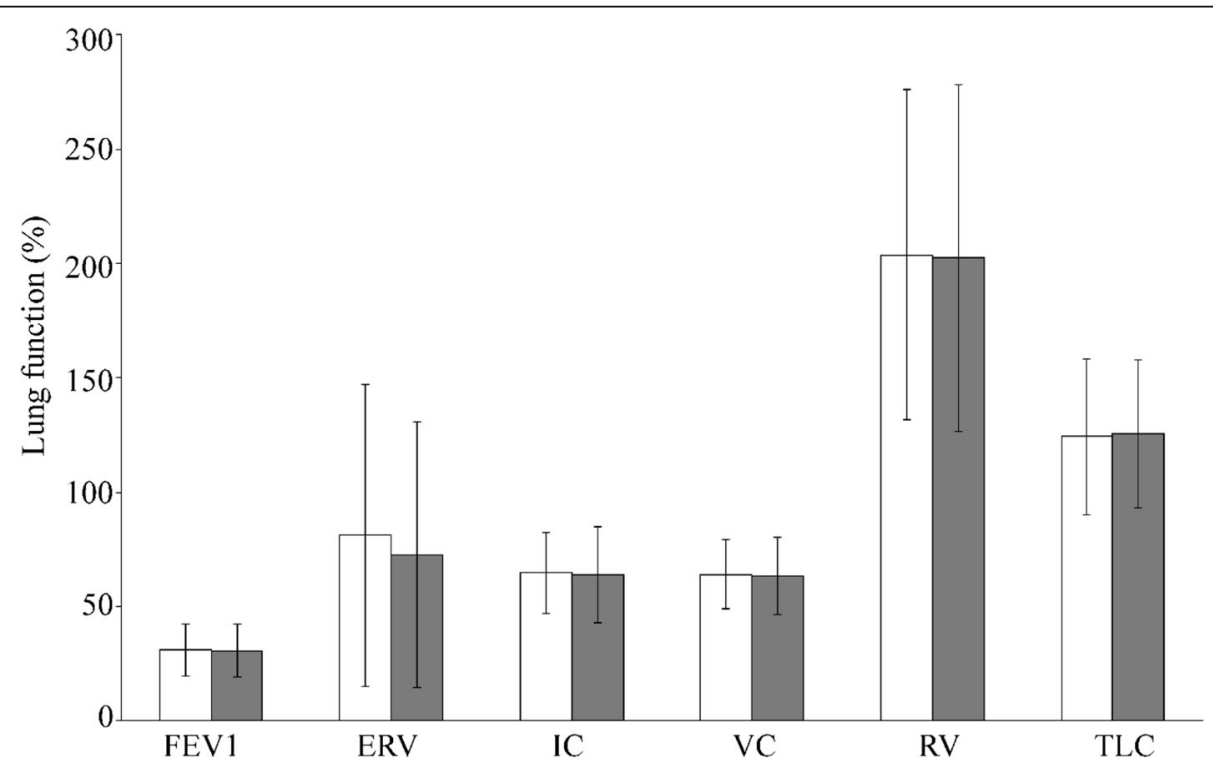

Fig. 5 Determination of lung function parameters under nasal high-flow oxygen therapy (HFOT) in 77 stable COPD patients. Dynamic and static lung parameters after both conventional oxygen therapy (COT; white bars) and HFOT (grey bars) were expressed in percent of the predicted value: FEV1 (forced expiratory volume in 1 s), ERV (expiratory reserve volume), IC (inspiratory capacity), VC (vital capacity), RV (residual volume), and TLC (total lung capacity) 
space. According to these results, $\mathrm{PaCO}_{2}$ should not be affected by tracheal pressure but solely by higher flow rates. This possibility, however, was contradicted by Mc Ginley et al. [13], explaining this HFOT-based effect by an increase in pharyngeal pressure. In essence, these findings point to the hypothesis of an overall improvement in oxygenation by HFOT, which has not been described in the literature until now $[1,3,25]$.

As far as safety parameters are concerned, it should be stressed that during HFOT neither deterioration of lung volumes, nor significant differences in DLCO, RAW levels or other adverse events were noted. The high level of patient satisfaction was deemed as a further success of the use of HFOT in the cohort. All patients rated HFOT as 'pleasant,' which is compatible with earlier studies stressing the improved comfort as based on low levels of dyspnoea and mouth dryness as well as a lack of restrictions in food ingestion or speaking [26]. This positive general evaluation was also supported by other observations, such as a reduction of dyspnoea attributed to a correction of hypoxaemia and a reduction of the respiratory rate and the humidification providing a higher secretion clearance and an improved mucociliary function in the airways [26].

Recently, the benefit of HFOT applications has been demonstrated by several reports, underlining that HFOT is well tolerated by patients with mild to moderate hypoxic respiratory failure [19]. Frat et al. [16] demonstrated improved survival rates among HFOT treated patients with acute hypoxaemic respiratory failure when compared to patients treated by COT or non-invasive ventilation. In patients with acute respiratory failure, the coordination of breathing-related movements of the rib cage and abdominal wall is often impaired, leading to respiratory muscle fatigue [27]. This thoraco-abdominal impairment of synchrony could be improved by HFOT in patients with mild to moderate respiratory failure [17]. Moreover, in patients with post-extubation respiratory failure, HFOT was as effective as non-invasive ventilation in avoiding reintubation of patients $[18,20]$.

Limitations of our study might be seen in the relatively small overall patient number, so that some constraints in delivering representative data similarly valuable for greater collectives cannot be fully excluded. In addition, the short-term regimen reduced to a single one-hour treatment might render some room for optimization, so that a third trial under varied conditions is presently in the planning phase (termed STIT-3 conceived as a longterm study). Another minor point of limitation might have been given by the uniform application of the single low flow rate of $15 \mathrm{~L} / \mathrm{min}$, which might possibly be even further optimised in future studies as currently flow rates up to $50 \mathrm{~L} / \mathrm{min}$ are reported to be used.

Overall, the study outcome is considered very promising leading to the following conclusions. We suggest
HFOT as a novel option of non-invasive treatment providing an efficacious and safe mode of oxygenation for COPD patients. Parameters being at least comparable or even more advantageous compared to COT included the lower level of oxygen requirement, the significant decrease in $\mathrm{PaCO}_{2}$, the conservation of lung functionality, and a high level of patient satisfaction. A reduction of oxygen requirement was seen in both patient groups, with an even more pronounced effect in normocapnic than in hypercapnic patients. Combined, the findings demonstrate various aspects of beneficial effects for both normo- and hypercapnic COPD patients using the novel HFOT regimen so that larger studies in the near future might expand on this set of data.

\section{Conclusions}

Short-term use of HFOT is safe in normocapnic and hypercapnic COPD patients. During HFOT lower oxygen levels were effective in correcting hypoxemic respiratory failure and reducing hypercapnia, leading to a reduced amount of oxygen consumption.

\begin{abstract}
Abbreviations
$\mathrm{AaDO}_{2}$ : Alveolar to arterial oxygen pressure difference; COPD: Chronic obstructive pulmonary disease; COT: Conventional oxygen treatment; DLCO: Diffusing capacity of lung carbon monoxide; ERV: Expiratory reserve volume; $\mathrm{FEV}_{1}$ : Forced expiratory volume in one second; FiO2: Fraction of inspired oxygen; FVC: Forced vital capacity; GOLD IV: Global Initiative for Chronic Obstructive Lung Disease IV; HFOT: Highflow oxygen therapy; IC: Inspiratory capacity; LTOT: Long-term oxygen treatment; $\mathrm{PaCO}_{2}$ : Partial oxygen pressure (arterialised); $\mathrm{PaO}_{2}$ : Partial carbon dioxide pressure (arterialised); RAW: Airway resistance; RV: Residual volume; SD: Standard deviation; $\mathrm{SpO}_{2}$ : Peripheral oxygen saturation; STIT-1: Short time TNI treatment 1 (normocapnic COPD patients); STIT-2: Short time TNI treatment 2 (hypercapnic COPD patients); STIT-3: Long time TNI treatment; TLC: Total lung capacity; TNI: Transnasal Insufflation; VC: Vital capacity; Vcex: Exspiratory vital capacity; Vcin: Inspiratory vital capacity; WHO: World Health Organization
\end{abstract}

\section{Acknowledgements}

We would like to thank TNI medical AG, Würzburg, Germany for the supply of HFOT devices and additional instrumentation, and Dr. Stefan Lang for medical writing assistance.

\section{Funding}

HFOT devices and additional instrumentation was provided by TNI medical $A G$, Würzburg, Germany. TNI had no influence on the rationale, design of the study, collection, analysis, and interpretation of data.

\section{Availability of data and materials}

The datasets used and analysed during the current study and supporting the conclusions of this article are available from the corresponding author on reasonable request.

\section{Authors' contributions}

HV made contributions to design, coordination, and acquisition of data, statistical analysis, analysis and interpretation of data. HV, MH, HW, TG, SO and CMK made substantial contributions to conception and design, acquisition of data, analysis and interpretation of data. SB made contributions to acquisition of data. Statistical analysis and logistic coordination was done by HV. HV, MH, SB, HW, TG, SO, AS and CMK has been involved in drafting the manuscript and revising it critically for important intellectual content. HV, MH, SB, HW, TG, SO, AS and CMK has given final approval of the version to be published and has participated sufficiently in the work to take public responsibility for appropriate portions of the content. HV, MH, SB, HW, TG, SO, AS and CMK agreed to be 
accountable for all aspects of the work in ensuring that questions related to the accuracy or integrity of any part of the work are appropriately investigated and resolved. All authors read and approved the final manuscript.

\section{Ethics approval and consent to participate}

Studies were registered at ClinicalTrials.gov NCT01686893 (STIT-1 [22]) and NCT01693146 (STIT-2 [23]) and approved and consented by the local ethics committee (Ethikkommission der Medizinischen Universität Innsbruck, Studienkennzahl UN3547, Sitzungsnummer 274/4.19).

All the individuals gave their written informed consent to participate.

\section{Consent for publication}

Not applicable.

\section{Competing interests}

Helene Vogelsinger received fees for lectures from TNI Medical AG, Würzburg and acts as a consultant for Linde Gas GmbH, Stadl-Paura. Michael Halank received personal fees for lectures from TNI Medical AG, Würzburg.

Heinrike Wilkens received fees for lectures from TNI Medical AG, Würzburg. Christian M. Kaehler acts as a consultant for TNI Medical AG, Würzburg. The other authors declare that they have no competing interests.

\section{Publisher's Note}

Springer Nature remains neutral with regard to jurisdictional claims in published maps and institutional affiliations.

\section{Author details}

'Pneumology, Internal Medicine II, Department of Internal Medicine, Medical University of Innsbruck, Innsbruck, Austria. ${ }^{2}$ Pneumology, Medical Clinic and Polyclinic, University Hospital Carl Gustav Carus, Dresden, Germany. ${ }^{3}$ Pneumology, Saarland University Medical Centre, Homburg, Germany. ${ }^{4}$ Department for Pulmonary Medicine, University Hospital Inselspital, Bern, Switzerland. ${ }^{5}$ Pneumology, Berner REHA Zentrum Heiligenschwendi, Heiligenschwendi, Switzerland. ${ }^{6}$ Pneumology, Lung Centre Southwest, Wangen im Allgäu, Germany.

\section{Received: 24 May 2017 Accepted: 10 November 2017}

\section{Published online: 17 November 2017}

\section{References}

1. Nishimura M. High-flow nasal Cannula oxygen therapy in adults: physiological benefits, indication, clinical benefits, and adverse effects. Respir Care. 2016;61(4):529-41.

2. Roca O, Hernandez G, Diaz-Lobato $\mathrm{S}$, et al. Current evidence for the effectiveness of heated and humidified high flow nasal cannula supportive therapy in adult patients with respiratory failure. Crit Care. 2016;20(1):109.

3. Porhomayon J, El-Solh AA, Pourafkari L, et al. Applications of nasal high-flow oxygen therapy in critically ill adult patients. Lung. 2016;194(5):705-14.

4. Halbert RJ, Natoli JL, Gano A, et al. Global burden of COPD: systematic review and meta-analysis. Eur Respir J. 2006;28(3):523-32.

5. Raherison C, Girodet PO. Epidemiology of COPD. Eur Respir Rev. 2009; 18(114):213-21.

6. Rycroft CE, Heyes A, Lanza L, et al. Epidemiology of chronic obstructive pulmonary disease: a literature review. Int J Chron Obstruct Pulmon Dis. 2012;7:457-94

7. Kessler R, Partridge MR, Miravitlles M, et al. Symptom variability in patients with severe COPD: a pan-European cross-sectional study. Eur Respir J. 2011; 37(2):264-72.

8. Nocturnal Oxygen Therapy Trial Group. Continuous or nocturnal oxygen therapy in hypoxemic chronic obstructive lung disease: a clinical trial. Ann Intern Med 1980;93(3):391-398.

9. Stuart-Harris C, Bishop JM, Clark TJH, et al. Long term domiciliary oxygen therapy in chronic hypoxic cor pulmonale complicating chronic bronchitis and emphysema. Report of the Medical Research Council working party. Lancet. 1981;1(8222):681-86.

10. Tsolaki V, Pastaka C, Kostikas K, et al. Noninvasive ventilation in chronic respiratory failure: effects on quality of life. Respiration. 2011;81(5):402-10.

11. Barnes PJ, Burney PG, Silverman EK, et al. Chronic obstructive pulmonary disease. Nat Rev Dis Primers. 2015;1:15076.
12. Braunlich J, Beyer D, Mai D, et al. Effects of nasal high flow on ventilation in volunteers, COPD and idiopathic pulmonary fibrosis patients. Respiration. 2013;85(4):319-25.

13. McGinley BM, Patil SP, Kirkness JP, et al. A nasal cannula can be used to treat obstructive sleep apnea. Am J Respir Crit Care Med. 2007;176(2):194-200.

14. Dysart K, Miller TL, Wolfson MR, et al. Research in high flow therapy: mechanisms of action. Respir Med. 2009;103(10):1400-5.

15. Spence KL, Murphy D, Kilian C, et al. High-flow nasal cannula as a device to provide continuous positive airway pressure in infants. J Perinatol. 2007; 27(12):772-5.

16. Frat JP, Thille AW, Mercat A, et al. High-flow oxygen through nasal cannula in acute hypoxemic respiratory failure. N Engl J Med. 2015;372(23):2185-96.

17. Itagaki T, Okuda N, Tsunano Y, et al. Effect of high-flow nasal cannula on thoraco-abdominal synchrony in adult critically ill patients. Respir Care. 2014:59(1):70-4

18. Kim JH. Can a high-flow nasal cannula substitute for noninvasive positive pressure ventilation in post-extubation respiratory failure? Korean J Intern Med. 2016;31(1):36-9.

19. Schwabbauer N, Berg B, Blumenstock G, et al. Nasal high-flow oxygen therapy in patients with hypoxic respiratory failure: effect on functional and subjective respiratory parameters compared to conventional oxygen therapy and non-invasive ventilation (NIV). BMC Anesthesiol 2014;14:66.

20. Yoo JW, Synn A, Huh JW, et al. Clinical efficacy of high-flow nasal cannula compared to noninvasive ventilation in patients with post-extubation respiratory failure. Korean J Intern Med. 2016;31(1):82-8.

21. Global Initiative for Chronic Obstructive Lung Disease. Pocket Guide to COPD Diagnosis, Management and Prevention 2016. http://goldcopd.org/pocketguide-copd-diagnosis-management-prevention-2016/. Accessed 10 June 2016.

22. ClinicalTrials.gov. Evaluation of Safety and Efficacy of Shorttime TNI Treatment in Patients With COPD (STIT-1) 2012. https://clinicaltrials.gov/ct2/ show/NCT01686893. Accessed 20 June 2016.

23. ClinicalTrials.gov. STIT-2: Evaluation of Safety and Efficacy of Short-time TNI ${ }^{\circledast}$ Treatment in Patients With COPD and Hypercapnia (STIT-2) 2012. https:// clinicaltrials.gov/ct2/show/NCT01693146. Accessed 20 June 2016.

24. Frizzola M, Miller TL, Rodriguez ME, et al. High-flow nasal cannula: impact on oxygenation and ventilation in an acute lung injury model. Pediatr Pulmonol. 2011:46(1):67-74.

25. Lawrence M. All you really need to know to interpret arterial blood Gase. 2nd ed. Philadelphia, PA: Lippincott Williams \& Wilkins; 1999.

26. Roca O, Riera J, Torres F, et al. High-flow oxygen therapy in acute respiratory failure. Respir Care. 2010;55(4):408-13.

27. Clergue F, Whitelaw WA, Charles JC, et al. Inferences about respiratory muscle use after cardiac surgery from compartmental volume and pressure measurements. Anesthesiology. 1995:82(6):1318-27.

\section{Submit your next manuscript to BioMed Central and we will help you at every step:}

- We accept pre-submission inquiries

- Our selector tool helps you to find the most relevant journal

- We provide round the clock customer support

- Convenient online submission

- Thorough peer review

- Inclusion in PubMed and all major indexing services

- Maximum visibility for your research

Submit your manuscript at www.biomedcentral.com/submit
) Biomed Central 